\title{
Cultura Cultura
}

Revista de Historia Terord das deaias - Revista de História e Teoria das Ideias

Vol. $26 \mid 2009$

0 Tempo das Revistas

\section{SOUTO, Maria Helena, História do Design em Portugal I}

Leonor Ferrão

\section{(2) OpenEdition}

Journals

Edição electrónica

URL: http://journals.openedition.org/cultura/570

DOI: $10.4000 /$ cultura. 570

ISSN: 2183-2021

\section{Editora}

Centro de História da Cultura

\section{Edição impressa}

Data de publição: 1 junho 2009

Paginação: 293-296

ISSN: 0870-4546

\section{Refêrencia eletrónica}

Leonor Ferrão, « SOUTO, Maria Helena, História do Design em Portugal I », Cultura [Online], Vol. 26 | 2009, posto online no dia 16 setembro 2013, consultado a 22 setembro 2020. URL : http:// journals.openedition.org/cultura/570 ; DOI : https://doi.org/10.4000/cultura.570 


\title{
SOUTO, Maria Helena, História do Design em Portugal I, Prefácio de José- -Augusto França, Lisboa: Edições IADE, 2009, 94 pp. + [50] il.
}

\author{
Leonor Ferrão
}

Importa, antes de mais, saudar uma publicação que se inscreve num registo disciplinar no qual escasseiam os contributos, embora o título prometa o que não cumpre. $O$ número romano aposto ao título História do Design em Portugal sugere o arranque de uma série subordinada à mesma temática, mas acaba por induzir em erro, ao fazer prever uma obra com outra extensão e coesão interna. Dispersos, subsídios ou contributos para a História do Design em Portugal seriam algumas das possibilidades para designar esta colectânea de ensaios historiográficos de curta dimensão, redigidos seguramente em momentos diferentes, embora essa informação não seja disponibilizada ao leitor: falta-Ihes um fio condutor, para além do que é sugerido pelo contexto disciplinar indicado no título, apesar de alguns textos se posicionarem em territórios de fronteira ou para além da fronteira do campo disciplinar do design. Falta, também, um texto que explicite os critérios que presidiram à selecção e ao alinhamento propostos (a "nótula" não cumpre essa função). O único propósito anunciado no pequeno texto introdutório é o de "dar aos estudantes de design uma ferramenta a partir da qual possam iniciar o seu conhecimento e as suas pesquisas sobre a história da disciplina no caso português" (p. 18). A complexidade dos textos e os espaços que deixam por preencher, se olharmos de novo para o título da colectânea, onde se anuncia uma narrativa estruturada sequencialmente, não parecem estar ao alcance da maioria dos estudantes de Design. Celebrar os quarenta anos do IADE, cumpridos em 2009 - propósito anunciado pelo coordenador das edições do IADE -, teria sido razão bastante para justificar esta publicação, embora, insista-se, continue a não justificar o título escolhido e, menos ainda, o desenvolvimento do ensaio final (pp.83-88): mais útil fora elaborar um texto sobre os fundamentos do IADE, sem ignorar o contexto e sem perder o foco no essencial, mostrando que a importância da instituição não ficou só a dever-se à sua circunstância. Se outras razões não houvesse, a efeméride justificaria, plenamente, que se desse a conhecer a sua história. Esperava-se, por isso, muito mais do que um alinhamento de imagens que não são tecidas com o texto e muito mais do que a enumeração de disciplinas e de professores, embora a autora procure articular 
estes dados com considerações mais ou menos avulsas sobre outros protagonistas (ou sobre o que é o Design). Acrescente-se que Helena Souto é professora do IADE e tem currículo científico e pedagógico muito relevante, pelo que dispensa condescendência na apreciação do seu trabalho. Dito isto, os textos mais interessantes são o ensaio "Desenvolvimento das estruturas metálicas" (pp. 41-50) e algumas páginas sobre Rafael Bordalo Pinheiro (pp. 57-71). A propósito deste último ensaio, discordamos da aplicação do conceito "design de exposições" (porque, no contexto, soa a anacronismo) - e constata-se, de novo, o desajuste entre o título e o desenvolvimento. Por exemplo, a autora não esclarece qual é a relação entre a obra de Bordalo Pinheiro (1846-1905) e a de Leal da Câmara (1876-1948), para além de um denominador que foi comum a outras personalidades artísticas, i.e., a suposta "influência geométrica", próxima do Modern Style e da Wiener Secession (conceitos que coincidem no tempo, mas que diferem em muitíssimos aspectos). Pelo meio, fala de raspão de Raul Lino (1879-1974), mas a formação, as notas de personalidade e os pressupostos estéticos e ideológicos de Bordalo e de Lino são dissemelhantes. A preocupação de Bordalo com a necessidade de requalificação estética e funcional da produção industrial parece-nos bem exposta, mas não é possível ignorar que parte significativa da sua produção para a fábrica das Caldas da Rainha assentou em peças únicas e que uma das suas linhas de inspiração, talvez a mais importante, não teve nada de vernacular, nem de "portuguesa": referimo-nos à influência da cerâmica de Bernard Palissy (c. 1510-c. 1590), pese embora que parte da temática acabou sendo "aportuguesada". Sumariando razões, ficou por traçar a genealogia formal e simbólica da cerâmica de Bordalo e por problematizar por que razão Bordalo Pinheiro cultivou várias linguagens. Dito de outro modo, ficamos sem saber se Bordalo foi um ecléctico por opção ou por imposição de alguns encomendadores. No ensaio "O debate entre engenheiros e arquitectos" (pp. 26-39) verifica-se de novo o desajuste entre o título e o desenvolvimento. De facto, não houve debate nenhum, pelo menos durante o século XVIII;e, mesmo durante o século XIX, tudo não terá passado de desabafos sem eco, como os de Joaquim Possidónio Narciso da Silva (1806-1896): a desproporção entre os hipotéticos opositores, em número e em notoriedade social, não autoriza o termo "debate". A equidade entre arquitectos e engenheiros, pelo menos no acesso a concursos públicos para provimento de vagas para técnicos de 1. a classe, só aconteceu nos anos 30 do século XX, por iniciativa do engenheiro Duarte Pacheco (1899-1943). Assim, o reconhecimento que faltou aos arquitectos, até ao consulado de Duarte Pacheco, manteve-se muito para além do razoável, se admitirmos que a razão primeira para esta realidade 
poderia justificar-se pela fraca qualidade do ensino de arquitectura ministrado nas escolas de Belas-Artes portuguesas. No entanto, os arquitectos portugueses diplomados nas Beaux-Arts de Paris também não lograram obter qualquer reconhecimento extra pela excelência artística e técnica da formação recebida, em muitos casos com bolsas de estudo do mesmo Estado que Ihes negava os lugares cimeiros na Administração Pública. Sobre estas questões, valeria a pena considerar os estudos de Maria Helena Lisboa, de mestrado (1996) e de doutoramento (2007) - o primeiro é citado (p.45), mas apenas a propósito do texto dedicado às estruturas metálicas. Em Portugal, ao contrário de outras nações europeias, a figura socioprofissional do engenheiro cresceu em importância desde que surgiu formação específica para este grupo profissional, também por causa das fragilidades (já apontadas) no ensino de arquitectura e, talvez, por omissão dos arquitectos, mas não terá sido apenas por estes motivos: a difícil conjuntura político-militar posterior ao golpe palaciano de 1 de Dezembro de 1640 e a carência de técnicos qualificados nas colónias ultramarinas foram favoráveis aos engenheiros, tal como o quadro da reconstrução da cidade de Lisboa, em contexto cultural do lluminismo (que valorizou a cultura técnica em detrimento da cultura artística). Poderíamos, ainda, se mais não houvesse, invocar a ausência de produção teórica em arquitectura e a falta de profissionais com a envergadura intelectual do mesmo nível de Luís Serrão Pimentel (1613-1679) e de Manuel Azevedo Fortes (1660-1749), engenheiros que se bateram pela dignificação do estatuto socioprofissional dos seus pares nas várias tribunas a que tiveram acesso. Neste momento, $\mathrm{e}$ reportando aos séculos XVII e (parte do?) XVIII, não é possível saber quais foram as razões para o silêncio dos arquitectos relativamente à sua condição de subalternos perante os engenheiros, pelo menos até Possidónio da Silva, embora haja os protestos do arquitecto José Manuel de Carvalho e Negreiros (1752-1815) nas suas Jornadas pelo Tejo (1792) e no Aditamento (1797) - todavia, Negreiros disparou em diversas direcções, inclusive sobre os arquitectos, nomeadamente sobre os diletantes (e não o eram todos?). Assim, tanto Negreiros como Possidónio terão sido atípicos, porque se formaram fora de Portugal e porque protestaram. O que pensariam os outros, que eram a maioria? Ao contrário dos seus colegas franceses, nomeadamente os que estavam sob a asa protectora da Academia Real de Arquitectura, os arquitectos portugueses, com formação na Aula de Arquitectura Civil do Paço da Ribeira, eram muito poucos (comparativamente com o número de engenheiros formados na Aula de Fortificação), e a maioria não passou do estatuto de "criado para todo o serviço" na Casa das Obras e Paços Reais. A própria encomenda arquitectónica privada não pri- 
mou pela exigência, pelo que as razões para a posição de desfavor dos arquitectos relativamente aos engenheiros não podem comparar-se, por exemplo, com a situação francesa, nomeadamente após a abertura da École Nationale des Ponts et Chaussées (1747). E, porque a recensão vai longa, termina-se com o que nos parece ser o melhor deste livro, o prefácio de José-Augusto França.Trata-se de um texto curto, que se lê de uma assentada e com imenso prazer. No lapso de uma respiração, França traça o essencial sobre o pouco que se conhece de história do design em Portugal, campo disciplinar que não é a sua "zona de conforto".É, por isso, de elementar justiça reconhecer o mérito de Helena Souto, em primeiro lugar, pela escolha do prefaciador e, em segundo lugar, por ter conseguido publicar os seus ensaios, o que não é fácil no actual panorama editorial; por fim, por ter sabido vencer o silêncio que costuma pairar sobre a maior parte da produção científica em Portugal nas áreas da história da arte (e do design). Espera-se, por isso, para breve uma História do Design em Portugal II, para não quebrar a linha de continuidade, com um subtítulo que possa enquadrar os conteúdos, sem prometer nem mais nem menos do que pode oferecer. 